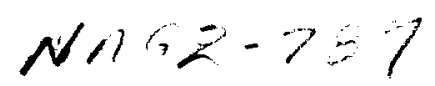

Mar. Fresh. Behav. Physiol., Vol. 27 (2-3), pp 95-110

Reprints available directly from the publisher

Photocopy permitted by licesnse only

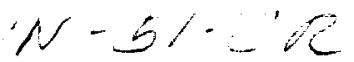

(C) 1996 OPA (Overseas Publishers Association) Amsterdam B.V. Published in The Netherlands under license by Gordon and Breach Science Publishers SA

\title{
THE TELEOST OCTAVOLATERALIS SYSTEM: STRUCTURE AND FUNCTION
}

\author{
ARTHUR N. POPPER \\ Department of Zoology, University of Maryland, College Park, MD 20742 \\ email:AP17@umail.umd.edu
}

(Received January 91995 ; in final form May 31 1995)

\begin{abstract}
This paper considers the detection of vibrational signals (including sound) by the two components of the octavolateralis system, the ear and mechanosensory lateral line. Together, these systems provide fishes with a good deal of information about their surrounding environment, and enable fishes to detect both predators and prey. While the mechanisms by which fishes and zooplankton produce and detect signals may differ, it is clear that the physical principles underlying the signals themselves are identical, no matter whether we are dealing with fish or zooplankton. Thus, an understanding of signal production and detection mechanisms by fishes can be of significant help in understanding how similar systems would function in zooplankton.
\end{abstract}

KEY WORDS: Fish, ear, lateral line, hearing, sound production, bioacoustics, sound

\section{INTRODUCTION}

Why be concerned with the sensory biology of adult fishes when the thrust of this symposium is on the sensory ecology and physiology of zooplankton, only a small portion of which include ichthyoplankton? There are several answers to this question. The first is that there are predator-prey interactions between the two groups, and if fishes can detect signals produced by zooplankton, this improves the survival of the predator and affects the prey. On the other hand, if zooplankton evolve signals not detectable by fishes, or if they themselves can detect potential predators, this improves their chances of survival. Thus, in understanding the ecology and behavior of zooplankton; it is necessary to have some appreciation of the sensory biology of major predators.

A second answer to the question is that in order to understand the sensory biology of zooplankton it is necessary to have some understanding of the physical aspects of the signals that are detected and emitted by these organisms, as well as of the physical aspects of the environment and the constraints imposed on signals by the environment. While the mechanisms by which fishes and zooplankton produce and detect signals may differ, it is clear that the physical principles underlying the signals themselves are identical, no matter whether we are dealing with fish, zooplankton, or marine mammals (or, for that matter, with terrestrial organisms).

The thrust of this paper will be to consider the octavolateralis system - the ear and lateral line of fishes. In doing so, I will first consider the relationship between the ear and lateral line and basic principles of underwater acoustics that affect both fish and zooplankton. This is followed by brief descriptions of the way in which fish use sound for communication and a more extensive discussion of how fishes detect sounds using 
the ear and the lateral line. Finally, the paper will consider what kinds of sounds fishes detect. Though the paper will discuss the ear and the lateral line, some emphasis will be placed on the auditory system since other papers in this symposium (e.g., Bleckmann et al., Volume 26) will provide additional insight into the function and behavior associated with the lateral line system.

In addition, this paper will not deal with zooplankton per se since this is the subject of many other papers in the symposium. However, it should be noted that the basic physical acoustic principles that affect the evolution and function of the octavolateralis system also had to affect the evolution and function of sensory systems in zooplankton. Thus, any consideration of how zooplankton detect or produce acoustic or hydroacoustic signals will certainly benefit from studies on fishes.

Since this paper is intended as an overview, no attempt has been made to be comprehensive in citing the extensive body of literature on fish bioacoustics or the octavolateralis system. The body of literature on sound production and the use of sounds by fish in behavior has been reviewed in several papers including those by Tavolga (1971), Demski et al., (1973), Fine et al,, (1977) and Myrberg (1981). More extensive reviews on fish hearing can be found in papers by Schellart and Popper (1992), Popper and Fay (1993), and Popper and Platt (1993). Again, although the lateral line is discussed in several of the papers mentioned above, more extensive discussions of the structure and function of the lateral line can be found in a volume by Coombs et al. (1989) and in papers by Coombs et al. (1992), Bleckmann (1993) and Montgomery et al. (in press).

\section{MULTIPLE SENSORY SYSTEMS}

It is important to understand that detection of vibrational signals (which includes sounds) by fishes really involves two sensory systems, the ear and the lateral line. (Note that references to the lateral line in this paper refer to the mechanoreceptive lateral line, as opposed to the electrosensory lateral line system that is found in many fish species.) Together, these are often referred to as the octavolateralis system. A single term is used since there are a number of features in common between the two systems (see Popper et al., 1992 for a review of the history of this term and the phylogenetic relationship between the ear and lateral line). Both systems use similar sensory hair cells as the transducing structure for signal detection. In addition, both respond to similar types of signals, and it is possible that the input from the ear and lateral line may overlap at some higher levels in the central nervous system (CNS), although they do not overlap at least up to the level of the midbrain (Schellart et al., 1984, 1992; McCormick, 1992).

The two components of the octavolateralis system have considerable functional overlap. The inner ear detects sounds from well below $50 \mathrm{~Hz}$ to, in some species, over $2,000 \mathrm{~Hz}$, and it also responds to positional information and motion of the body (vestibular senses) (e.g., Platt, 1983; Popper and Platt, 1993). The lateral line responds to 'the net motion between the fish's body and the surrounding water (e.g., spatial nonuniformities of the flow field - see Bleckmann, 1993 and Montgomery et al., in press), including stimuli produced by swimming fish and other organisms, from several hundred $\mathrm{Hz}$ down to close to DC (e.g., Coombs et al., 1989, 1992; Bleckmann et al., 1991b). An important difference between the two systems is the distance from the fish over which they detect signals. The lateral line detects signals close to a fish (e.g., within one or two body lengths) while the ear detects signals to considerable distances from the 
fish (e.g., Kalmijn, 1988, 1989). Many signals can be thought of in terms of stimulating both the ear and the lateral line. In fact, from the perspective of modifying the behavior of fish with sound, which sensory system is involved with the response is probably irrelevant.

\section{UNDERWATER SOUND}

It is important to consider underwater acoustics briefly before any further discussion of the octavolateralis system. Much of the literature often refers to the acoustic near field and acoustic far field (see van Bergeijk, 1967 for one of the classic discussions; also Kalmijn, 1988, 1989; Rogers and Cox, 1988). In the near field, particle displacement (which is vectorial and thus has a directional component) includes a hydrodynamic flow of the water as a consequence of the motion of the source. The far field particle displacement is only that molecular motion accompanying the far field pressure component of the signal. The measure often used for the transition between near- and far field is a function of $\lambda / 2 \pi$ ( $\lambda=$ wavelength) for a monopole source (pulsating sphere), which is approximately $1 / 6$ th of a wavelength of the sound frequency, but its precise distance depends upon the detailed structure of the sound source (e.g., Harris and van Bergeijk, 1962; Siler, 1969). Sound sources differ in the way they radiate energy. Consequently, the attenuation rates of the pressure and particle displacement components of the signals differ, depending upon the source and the distance from the source. Within the near field, signals generated with a complex source such as a "dipole" (a vibrating sphere approximating a swim bladder producing sound), have the most rapid attenuation of signals as they leave the source, while signals from a monopole have less rapid attenuation (see Harris and van Bergeijk, 1962; van Bergeijk, 1967; Kalmijn, 1988, 1989). Moreover, for both monopole and dipole, near field velocity and displacement attenuate more rapidly than does near field pressure $\left(1 / \mathrm{r}^{3} \mathrm{vs} 1 / \mathrm{r}^{2}\right.$ for a dipole and $1 / r^{2}$ vs $1 / \mathrm{r}$ for a monopole). However, in the acoustic far field particle displacements (velocities) and sound pressure from all sources attenuate as $1 / \mathrm{r}$.

By way of example, for a $100 \mathrm{~Hz}$ signal produced by a monopole source, the wavelength in water is $15 \mathrm{~m}$ (the speed of sound in water is approximately $1500 \mathrm{~m} / \mathrm{sec}$ ). The transition between the near- and far fields $(\lambda / 2 \pi)$ is approximately 2.4 meters from the sound source. Even if we assume that a fish is quite sensitive to the particle displacement, it is unlikely that the particle displacement component of a $100-\mathrm{Hz}$ signal would be detectable beyond about $2 \mathrm{~m}$ from the source unless the fish were exceptionally sensitive. The distance will be affected by sound intensity as well as by the displacement sensitivity of the fish.

It must be emphasized that near- and far field components do not suddenly change at the point of $\lambda / 2 \pi$ and that some fishes may be sensitive to hydrodynamic motions well into the far field, while others may be insensitive even in the outer part of the near field. In fact, pressure and particle displacement are present in both the near- and far fields, but particle displacement predominates in the near field and pressure predominates in the far field. The rate of attenuation of pressure and particle displacement differ, with particle displacement attenuating much more rapidly in the near field than does pressure. This provides a very substantial particle displacement gradient with increasing distance from the source in the near field.

The biological significance of these differences in the near and far field effect depends upon how readily a particular species can detect the particle displacement component 
of a signal with the ear vs. the lateral line. If the fish ear is very sensitive to particle displacement, then it may detect the signal for a considerable distance from the source. If the fish ear is not very sensitive to particle displacement, it will not detect the signal even as far as the transition point. The lateral line, in contrast, detects particle displacement gradients along the length of a fish (e.g., Denton and Gray, 1989, 1993). Since the gradient is greatest in the acoustic near field, the primary stimulus appropriate for this endorgan will only be found quite close to the source. Thus, if the fish is detecting sounds with the ears, it may be possible to detect particle displacement at a distance from the source that is a function of the initial sound level and ear sensitivity. However, initial sound level is not as relevant for detection by the lateral line since particle displacement gradients may not be sufficiently great in the far field to be detectable for a fish. While sound is important for communication behavior in a variety of species, sounds also are produced as a side-effect of other behaviors such as feeding or locomotion (see Moulton, 1963; Tavolga, 1971). (In fact, unintentional sounds may also be produced by zooplankton, thereby providing a signal to predators about their presence and location.)

Another critical aspect of underwater acoustics that is relevant to fishes that live in shallower water such as rivers and streams is that the attenuation rates of sounds, and particularly of low frequencies, is a function of water depth (Rogers and Cox, 1988). In shallow water there is far more attenuation of low-frequency sounds (both pressure and particle displacement components) than in deep water (Rogers and Cox, 1988). The lowest frequency that can be propagated depends upon water depth - the deeper the water, the lower the frequency that can be propagated. For example, Rogers and Cox (1988) show that the lowest frequency that will be propagated in water $1 \mathrm{~m}$ deep is about $300 \mathrm{~Hz}$, while in water $10 \mathrm{~m}$ deep the lowest frequency would be approximately $30 \mathrm{~Hz}$. The specific cut-off frequency depends upon the nature of the bottom (e.g., rock, mud, etc.), but the cut-off frequency for other bottoms is lower than for the example used (which is for rocky bottoms). Because of this lack of propagation of low frequencies in shallow water, it is likely that fish in such an environment only detect sounds that are extremely close to them.

\section{ACOUSTIC BEHAVIOR}

Acoustic communication has been well documented for many fish species (reviewed in Tavolga, 1971; Demski et al., 1973; Fine et al., 1977; Myrberg, 1981). As pointed out by Tavolga (1971), sound is a particularly useful channel for underwater communication since acoustic signals are not affected by murkiness or darkness of the environment, sound travels rapidly over long distances, is highly directional, and sound is not particularly affected by rocks or coral reefs (as long as they are small relative to the wavelength of the sound). In some species, such as toadfish (Opsanus), sounds are used over long distances by males to "call" females during the mating season (Winn, 1967). In other cases, such as the goby Bathygobius soporator, low intensity sounds are used to communicate between males and females that are very near one another (Tavolga, 1958). It has become clear from these studies that fish sounds are quite variant and depend upon the species. In addition, individual species may have more than one type of sound, with different sounds used in different behavioral contexts (Tavolga, 1971; Fine et al., 1977). 
Sounds are produced intentionally in a large number of species, although the emission mechanisms and the behavioral context of the sounds varies inter-specifically (Tavolga, 1971)."Stridulatory" sounds are produced by moving or grinding of body parts against one another such as using pharyngeal teeth or other hard body parts (similar mechanisms are found in snapping shrimp - Moulton, 1963). Other species produce sounds by directly or indirectly involving the swim bladder. Some of these "swim bladder sounds" consist of short bursts of broad-band noise (especially those produced using stridulatory mechanisms), while others are tonal and contain a fundamental frequency and multiple harmonics (e.g., Tavolga, 1971; Demski et al., 1973; Fine et al., 1977).

Perhaps the most elegant study of the use of sound in behavior was done by Myrberg and his colleagues on damselfish (family Pomacentridae) (e.g., Spanier, 1979; Myrberg and Spires, 1980). Several species live conspecifically on reefs and use sounds to defend territories, including nests. Each species has a sound that differs in frequency and in pulse repetition rate. Behavioral studies showed that species can discriminate between sounds of conspecifics and heterospecifics based on differences in pulse rate, and there is even good evidence for individual recognition (Myrberg and Riggio, 1985).

\section{STRUCTURE OF THE OCTAVOLATERALIS SYSTEM}

\section{The Mechanoreceptive Lateral Line}

The structure and function of the mechanoreceptive lateral line was reviewed by Coombs et al., (1989, 1992). The lateral line system consists of a series of receptors (called neuromasts) located over the body surface of a fish (Figure la). Each of the neuromasts contains sensory hair cells that are very similar to those found in the fish ear. The cilia on the sensory hair cells project into an overlying gelatinous cupula which acts as a "sail" in response to fluid motions of the water. Movement of the cupula produces bending of the cilia on the hair cells, and this results in stimulation of the sensory hair cells. Some of these receptors lie within canals that run along the fish's body (canal neuromasts), while other receptors, often called "free (or superficial) neuromasts," are located in pits or directly on the body surface (Figures le, f, g).

There appear to be some differences in the functional response characteristics of the two parts of the lateral line (Münz, 1989). Differences in canal vs. free neuromasts include the frequency range over which they respond (with canal neuromasts responding to higher frequencies than free neuromasts) (Münz, 1989). The functional basis for these differences are not fully understood, but they may be related to variation in sizes of the sensory epithelia in the canals and free neuromasts, the number of hair cells (e.g., Denton and Gray, 1989), and/or to differences in certain aspects of the sensory hair cells found in the canal and free neuromasts (Song et al., 1994).

While not a great deal is known with regard to the structure of the lateral line system as it correlates with the ecology and behavior of fishes, it has been suggested that the animal's life style or hydrodynamic conditions of their environment may be related to the peripheral structure of the system (Dijkgraaf, 1962). Dijkgraaf (1962), in a classic paper on the structure and function of the lateral line, suggested that fishes that are active swimmers and/or that live in flowing water have a well-developed canal system, whereas those species that do not swim extensively, and/or which live in calm waters, 


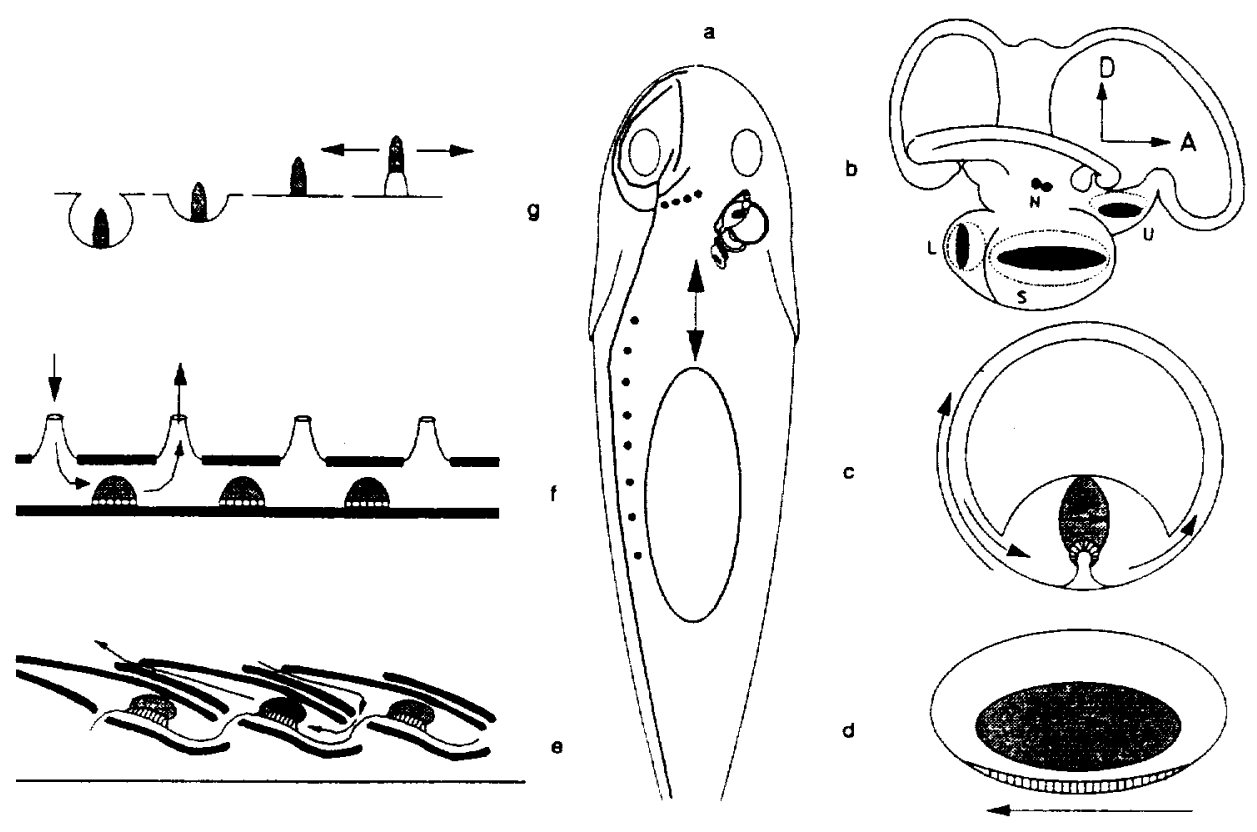

Figure 1 Schematic illustrations of the components of the octavolateralis system in a typical teleost fish. (a) Dorsal view of a fish showing the receptor organs discussed. The mechanoreceptive lateral line, including the canals (thick lines) and free neuromasts (small dark circles) are shown on the left side of the body. The inner ear with its semicircular canals and otolith organs (see enlargement in "b" and Figure 2) are shown on the right side of the body. The large oval in the abdominal cavity is the swim bladder. (b) An enlargement of the right ear (A-anterior; D-dorsal) showing each of the sensory receptors (represented in black) and their associated otoliths (dotted outlines). Each of the three semicircular canals has a sensory cristae (see "c" and Figure 2). The ear also has three otolith organs, the saccule (S), utricle (U) and lagena (L). Many species also have an additional macula neglecta (N), the function of which is not known in teleosts. (c) Schematic section of one semicircular canal showing the crista ampullaris (bottom) at the base of a narrow fluid-filled duct. Motion of the in the canal fluid (which is produced by rotational motions of the head - see Platt, 1983) results in a bending of the cupula (shaded area) above the sensory epithelium and the embedded cilia of the sensory hair cells. (d) Schematic representation of an otolithic endorgan showing the otolith (shaded) overlying a sensory epithelium. As described in the text, the otolith and epithelium move out of phase with one another, resulting in a shearing action on the sensory cells and a resultant stimulation of these cells. (e) Usual arrangement of the trunk canal of the mechanoreceptive lateral line showing neuromasts embedded within the scales. Each neuromast contains many sensory hair cells. The cupula overlying each neuromast "fills" the canals and any fluid motion within the canal results in a bending or shearing of the cupula relative to the sensory epithelium and a bending of the embedded cilia of the sensory hair cells. The arrows show the flow paths. (f) Mechanoreceptive lateral line canals of the head region. A neuromast lies between each pair of pores into the canal. Differences in pressure at two pores results in a fluid flow in the canal between the pores. $(\mathrm{g})$ Superficial mechanoreceptive neuromasts have a range of locations from being embedded within pits to being on the surface to being above the surface. In each case, the cilia of the sensory hair cells are embedded within a gelatinous cupula which bends in response to net water motion around the fish. (Figure from Platt, Popper, and Fay 1989).

have a less well developed canal system and a more highly developed free neuromast system. While this correlation does not always hold, Dijkgraaf (1962) suggested that the canals may help protect the sensory system from excess environmental stimulation resulting from extensive motion of the fish or its surrounding environment. 


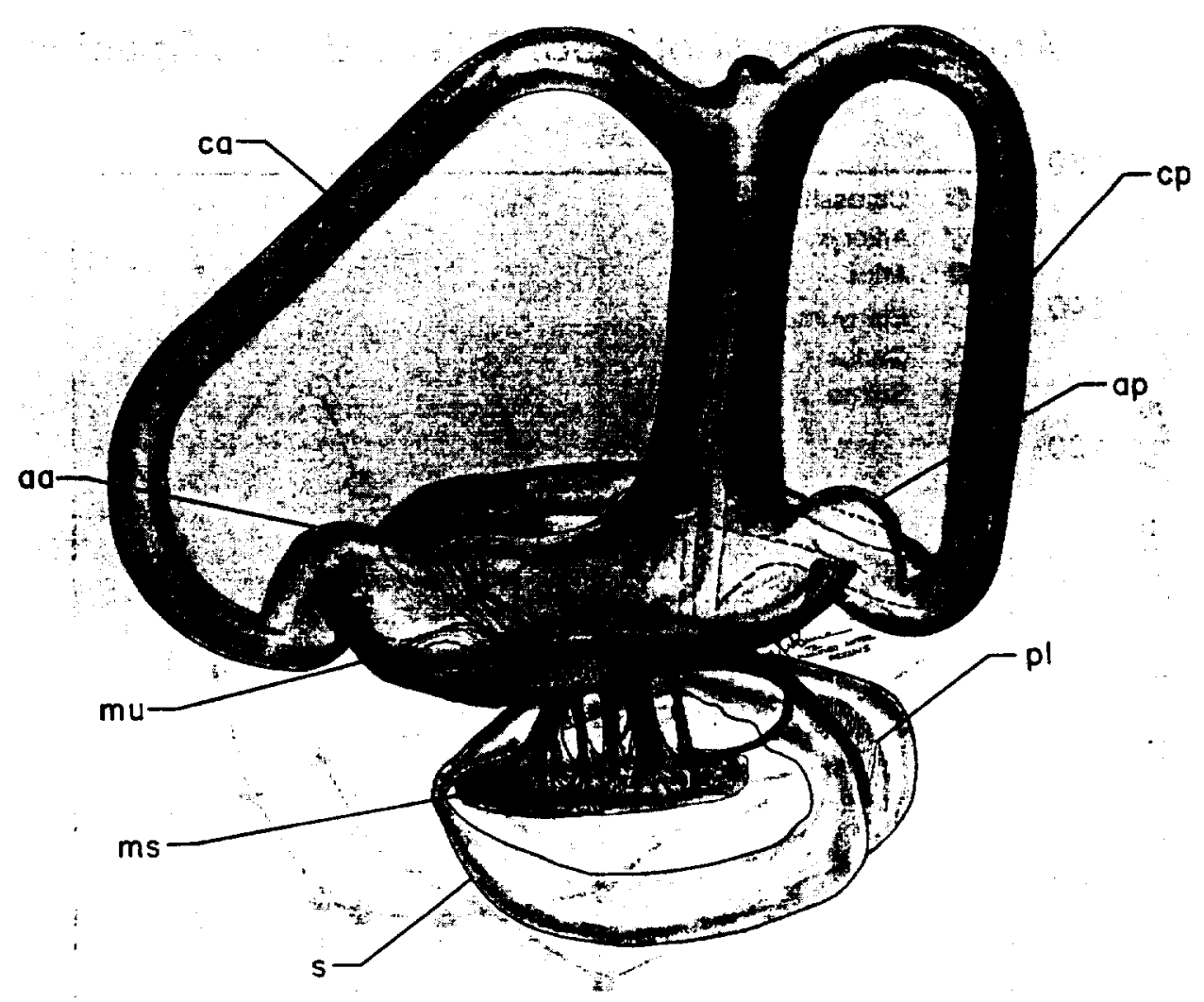

Figure 2 The ear of the salmon, Salmo salar, redrawn from Retzius (1881). aa - crista (sensory region) of anterior semicircular canal; ap - crista of posterior canal; ca - anterior semicircular canal; cp - posterior canal; ms - sensory epithelium of saccule; mu - sensory epithelium of utricle; pl - lagena; s - saccule.

The Ear

The ear of fishes has many similarities to the mammalian ear. It consists of three semicircular canals which serve to detect angular accelerations (head motions) and three pouches - called otolithic regions or end organs - the saccule, utricle and lagena (Figures $1 \mathrm{~b}, \mathrm{~d}, 2$ ). The otolithic end organs each have a sensory epithelium which contains sensory hair cells that are very similar to those found in the fish lateral line and the mammalian inner ear (e.g., Wersäll, 1960). Each otolithic end organ also contains a single, very dense, calcified otolith. The ciliary bundles on the apical ends of the sensory cells contact the otolith and, as will be discussed below, relative motion between the otolith and sensory hair cells results in the detection of signals.

The swim bladder (Figure la) is also involved in sound detection, as well as sound production, in many species. The physical relationship between the ear and swim bladder has a significant effect on sound detection capabilities of fishes (see Popper and Coombs, 1982). Species that have intimate coupling between the swim bladder and 


\section{Auditory Thresholds for Selected Fish Species}

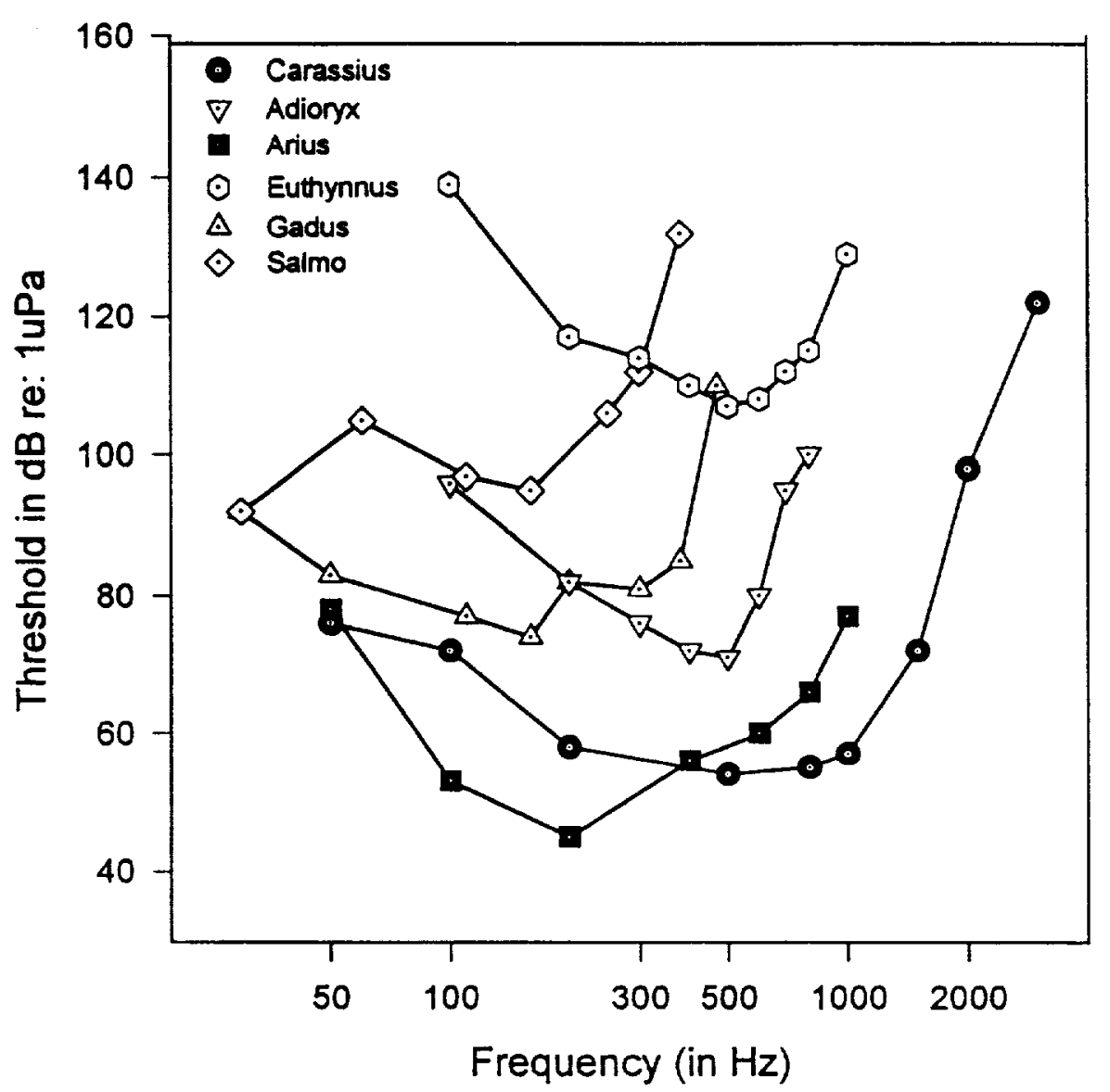

Figure 3 Auditory thresholds for representative species of teleost fishes. Two of the species, Carassius auratus (from Jacobs and Tavolga, 1967) and Arius felis (Popper and Tavolga, 1981) are otophysans and hearing specialists (solid symbols). Both species have Weberian ossicles connecting the swim bladder to the inner ear. The cod, Gadus morhua (Chapman and Hawkins, 1973), has a swim bladder than ends in close proximity to the ear. The squirrelfish Adioryx xantherythrus (Coombs and Popper, 1979), the Atlantic salmon, Salmo salar (Hawkins and Johnstone, 1978) and the tuna Euthynnus affinus (Iversen, 1969) are considered non-specialists. This species of tuna does not have a swim bladder. All data were originally determined in $\mathrm{d} B$ re: $1 \mu$ bar and have been converted to dB re: $1 \mu$ Pascal.

inner ear, such as the goldfish, are able to detect a wider frequency range and signals at lower intensities than fishes, such as salmonids, where there is no intimacy between the ear and swim bladder (Figure 3) (see below). 
Direct stimulation of the ear by particle motion set up by the sound source

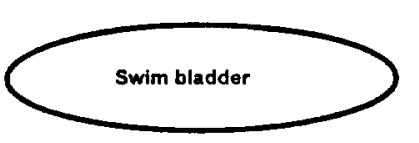

Otolith organs of the ear
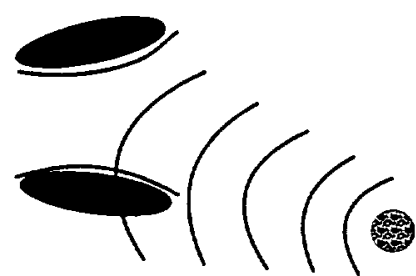

Sound source

Indirect stimulation of the ear by re-radiation of the pressure signal by the swim bladder

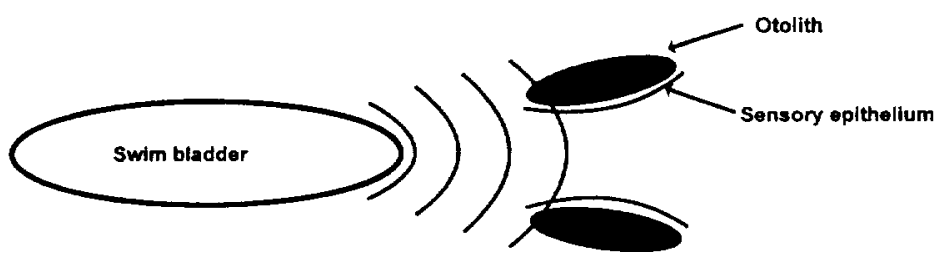

Figure 4 Modes of stimulation of the ear of a teleost fish. Top shows the "direct" pathway whereby particle displacement from a sound source (e.g., the swim bladder of another fish producing a sound, claw closing of a snapping shrimp) causes relative motion to occur between the sensory epithelium of the otolithic end organs of the ear and the otolith. The motion of the otolith is towards and away from the direction of the sound source The lower panel shows the response of the swim bladder to the pressure component of the signal produced by the same sound source (not shown). Because the swim bladder contains air, the walls of the chamber vibrate in response to the pressure signal and serve as a sound source which re-radiates particle displacement to the ears. The otoliths of both ears move symmetrically (as opposed to the direct stimulation) since the sound source, in this case, is directly between the two ears.

There is evidence to suggest that each of the otolithic end organs participates both in sound detection and in responding to vestibular stimulation (i.e., motions of the body with respect to gravity) and that the specific roles of each endorgan may vary in different species (reviewed in Platt, 1983; Popper and Platt, 1993). Thus, the saccule may be the primary hearing endorgan in otophysan fishes (e.g. cyprinids, silurids), while the utricle is likely to be the major sound receptor in Clupeiform fishes (these data are extensively reviewed in Platt and Popper, 1981; Fay, 1988a; Schellart and Popper, 1992). It is very likely that sound detection in many other species involves the saccule and, to a lesser degree, the lagena, although the data are less clear than for the otophysans and clupeids. There is also reason to believe that the utricle in many of these species is involved with source localization (see Schellart and Popper, 1992; Popper and Fay, 1993). Still, the specific role(s) of different end organs is unclear except in the herringlike fishes where the utricle is clearly involved in sound detection and in the otophysan fishes where the saccule is connected to the wall of the swim bladder and so presumed to be a pressure-detecting endorgan. 
There is also substantial interspecific variability in the structure and function of the ear and how fishes detect sounds (e.g., Popper, 1977; and reviewed in Popper and Coombs, 1982; Popper and Platt, 1993). This variability needs to be taken into account when considering sound detection by any particular species. As pointed out by Platt and Popper (1981), one cannot generalize and refer to "the" fish ear or auditory system since there is so much interspecific variability, particularly in the saccule. Behavioral, morphological, and physiological data support the argument that fishes may have evolved multiple ways to detect and process sounds. This is not surprising considering the wide range of habitats in which fishes are found, and it also makes the problem of analyzing and understanding fish hearing more complex (e.g., Schellart and Popper, 1992).

\section{SOUND DETECTION}

\section{Sound Detection Mechanisms of the Ear}

The significance of the presence of sound pressure and particle displacement for a fish is that some species, such as the goldfish (or other otophysan fishes), can detect both forms of energy, while other species may primarily respond to particle displacement with only a limited detection of pressure (e.g., Fay and Popper, 1974, 1975). In fact, it has been argued that fishes able to detect both pressure and particle displacement (species such as the goldfish) may have two different sound detection "pathways" to the ear, the "direct" and "indirect" (Figure 4) (Fay and Popper, 1975; Popper and Fay, 1993).

The "direct" pathway (Figure 4, top) is for detection of particle displacement through direct stimulation of the inner ear and results from relative motion between the sensory epithelium of the inner ear and the overlying otolith (Figure 1d). Relative motion arises because the body of a fish (including the sensory epithelia of the ear) is essentially acoustically transparent since its density is about the same as that of water. Thus, the body moves in a sound field along with the rest of the water mass. However, the otoliths are far denser than the rest of the body and, as a consequence, they move out of phase with the body and the sensory epithelium of the ear. This differential motion results in a shearing action on the cilia of the sensory hair cells (which are embedded in an "otolithic membrane" that connects the sensory epithelium to the otolith) and results in stimulation of the sensory hair cells.

The direct pathway is most likely operative in all fishes, and can affect any of the otolithic end organs. However, fishes that only use the direct pathway probably only detect sounds to a few hundred $\mathrm{Hz}$ and with fairly poor sensitivity - that is, they can only detect relatively loud sounds (Fay and Popper, 1975; Schellart and Popper, 1992).

The "indirect" pathway (Figure 4, bottom) involves detection of the pressure component of the acoustic signal. Pressure does not stimulate the inner ear directly, but it does set gas in the swim bladder (or other gas bubbles) into motion. The gas bubble then becomes a signal source and re-radiates the energy induced in it, generating its own near- and far field. If the bubble is sufficiently close, or otherwise acoustically coupled, to the ear, there is little attenuation of the particle displacement. This particle displacement can then cause otolith motion relative to the sensory epithelium. Without such coupling, the energy from the gas bubble attenuates sufficiently rapidly so that it does not affect the inner ear.

Fishes that use both direct and indirect stimulation of the ear are often referred to as hearing specialists, whereas fishes that primarily detect signals via the direct path are 
called non-specialists. Hearing specialists include members of the superorder Otophysi, all of which have a series of bones, the Weberian ossicles, that acoustically couple the swim bladder to the inner ear. Other hearing specialists include a number of diverse taxa including some squirrelfish (Holocentridae), clupeids, mormyrids, and anabantids. All of these species share a common characteristic in having some kind of rostral extension of the swim bladder that brings it into close proximity to the saccule (or to the utricle in clupeids), thereby increasing acoustic coupling with the ear (e.g., Popper and Coombs, 1982). This enhanced coupling is not present in the non-specialists. Nonspecialists make up the majority of teleost species and they either do not have a swim bladder (e.g., pleuronectids, some scombrids) or the rostral end of the swim bladder terminates a considerable distance from the ear.

\section{Signal Detection by the Lateral Line}

The lateral line detects the near field component of the sound field (e.g., Harris and Van Berjeijk, 1962; Kalmijn, 1988, 1989). It has been suggested that the lateral line is involved in a variety of behaviors that involve detection of local water flows, such as obstacle avoidance, intraspecific communication, detection of prey on the water surface, and schooling (e.g., Dijkgraaf, 1962; Bleckmann, 1988, 1993; Coombs and Janssen, 1989; Hassan, 1989; Montgomery et al., in press). In all cases, the fish are apparently detecting low frequency signals (less than $1 \mathrm{~Hz}$ in some cases up to at least 100 or $200 \mathrm{~Hz}$ ) that are produced by sources that are close to the fish (e.g., within one body length; - Kalmijn, 1988). It is important to note that the perception of signals by the lateral line is quite different than any perceptual capability of humans (just as is electroreception by fishes).

The "sensation" of signals through the lateral line cannot properly be called "hearing" since that implies certain things based upon human experience. Platt et al. (1989) have contributed the word "sven" to describe perceptual function of the lateral line. The term honors Professor Sven Dijkgraaf, one of the true pioneers in the study of the lateral line.

\section{What Do Fishes Hear?}

Sound detection capabilities of fishes are most often measured using behavioral paradigms that are very similar to those used to study hearing in other vertebrates (e.g., see Tavolga and Wodinsky, 1963; Jacobs and Tavolga, 1967; Fay, 1985; reviews of data in Fay, 1988a). The bandwidth of hearing (range of detectable frequencies from lowest to highest detectable) and sensitivity (lowest sound level that can be detected reliably) varies considerably among species (Figure 3). Earlier work suggested that the low frequency limit for hearing was around $50 \mathrm{~Hz}$, although this is clearly not a "real" value in that it often marks the lowest limits of the apparatus used to produce sounds and not the lowest frequency that can be detected by a fish. More recent work by Karlsen $(1992 \mathrm{a}, \mathrm{b})$ suggest, in fact, that some species of fish use their ears to detect infrasound. A significant factor in stating the lowest frequencies detectable by a fish is the problem of overlap between the ear and lateral line at frequencies below 100 to $200 \mathrm{~Hz}$. Of course, from the standpoint of studying the behavior of a fish, it is not necessarily important whether the stimulus is detected by the ear or lateral line. What is more important is whether the fish responds or does not respond to the signal.

The species most widely studied with regard to hearing has been the goldfish, Carassius auratus, which can detect tones from below $50 \mathrm{~Hz}$ to about $3,000 \mathrm{~Hz}$ with best hearing from about $200 \mathrm{~Hz}$ to $1,000 \mathrm{~Hz}$ (Figure 3). Similar results are found for 
other hearing specialists, such as Arius felis (a marine catfish) (Figure 3; see Fay, 1988a). In contrast, non-specialists generally have poorer hearing capabilities than specialists. For example, the Atlantic salmon (Salmo salar) can detect sounds from 32 to $380 \mathrm{~Hz}$, and best sensitivity is in the range of 100 to $200 \mathrm{~Hz}$ (Figure 3) (Hawkins and Johnstone, 1978). These results are similar to those found in other non-specialists such as Adioryx (squirrelfish, family Holocentridae) and the tuna Euthynnus affinus, a species that lacks a swim bladder (Figure 3).

The ability to detect pure tones, as illustrated in Figure 3, tells something about the frequencies at which an animal is most sensitive as well as about the range of frequencies (bandwidth) of an auditory system, but most biologically relevant signals are not pure tones (e.g., Fish, 1954). Moreover, under natural conditions the role of the auditory system is to detect signals in the presence of other signals (e.g., background noise) and to discriminate between signals, such as is done by the pomacentrids, a group of marine fish that are not considered to be hearing specialists (Myrberg and Spires, 1980).

Behavioral studies are used to measure hearing capabilities that more nearly approximate the tasks that the auditory system must accomplish (reviewed by Fay, 1988a; Popper and Fay, 1993). These tasks include detection of signals in the presence of noise and the ability to discriminate between sounds that differ in intensity, frequency, distance, or direction. However, while data on pure tone sensitivity are available for over 50 species (see Fay, 1988a), data on detection of signals in noise and discrimination are available primarily for Carassius, while far fewer data are available for a limited number of other species. Those data that are available (reviewed in Fay, 1988a) suggest that non-specialists may not be able to discriminate as well as specialists, although a number of non-specialists, including the Atlantic salmon, can detect signals in the presence of a masker (Hawkins and Johnstone, 1978). The ability of goldfish to discriminate between frequencies and intensities, and to detect signals in the presence of noise, while not as good as for humans, is still considered to be well within the overall vertebrate range for these capabilities (see Fay, 1988b).

While we might expect that fishes that use sound for communication would hear well, it has also been demonstrated that many fishes that hear well are not known to use sounds for communication. Why do these species, which include the goldfish, have good auditory capabilities? While a specific answer to this question is not known, it has been suggested that fishes, including presumably "mute" species such as the goldfish, use sound not only for communication, but also for gaining a general "impression" about their environment. The aquatic environment contains many ambient sounds sources such as waves breaking on a beach, water sounds from rain, etc. (e.g., Schellart and Popper, 1992) that could provide a fish with information about its overall environment. In essence, it has been suggested that fishes use ambient noise to gain an "image" of their environment (e.g., Myrberg, 1981; Popper and Fay, 1993), much as humans learn about their environment from ambient sounds (Bregman, 1990). Clearly, one major role of the auditory system is to provide such an environmental image even under conditions where other sensory information, such as visual signals, are not available.

\section{Detection of Sound Source Direction}

One of the most important roles for the auditory system is to detect the presence and location of a predator or prey, or objects in the environment. The capabilities and 
mechanisms for determination of sound source location, or sound localization, is best understood for terrestrial vertebrates (Brown, 1994). While it has been argued that fishes should not be able to localize sounds (van Bergeijk, 1967), more recent, albeit limited, data indicate that at least several species of fish can do so (e.g., Hawkins and Sand, 1977; Schuijf, 1975, 1981; Buwalda et al., 1983; Schuijf and Hawkins, 1983). Investigations of the cod, Gadus morhua, the one species for which there is any body of data on sound localization, indicates that this species can discriminate between sounds that are at least as close as 20 degrees to one another (Chapman and Johnstone, 1974), and that such discrimination occurs not only in the horizontal plane, but also in the vertical plane (Hawkins and Sand, 1977). In comparison, humans in air can discriminate sounds that are as close to one another as 1 degree (reviewed in Brown, 1994), while the bottlenosed dolphin, Tursiops truncatus, can discriminate sounds that are less than 1 degree apart in water (Renaud and Popper, 1975).

The bulk of the localization data for fishes is for the cod, and so we have very little understanding of the comparative abilities of fish to localize. In particular, we do not have any real idea of differences in localization capabilities between hearing specialists (such as the cod) and non-specialists, and between localization in the near field vs the far field. Significantly, there are not sufficient behavioral data on a single species (including the cod) to actually define its capabilities.

Another major deficiency in our understanding of sound localization by fishes concerns the mechanism by which the cod, or other species, determine sound source direction and/or distance. What is certain, however, is that the mechanisms used by terrestrial animals for sound localization, the comparison of sounds that reach the two ears, is not viable for fishes since the speed of sound in water precludes there being interaural differences in acoustic signals (van Bergeijk, 1967). Instead, the most widely accepted models of sound localization mechanisms (e.g., Schuijf and Buwalda, 1980; Buwalda, 1981; Popper et al., 1988; Rogers et al., 1988; Schellart and Buwalda, 1990) suggest that for fishes to localize sound well they need both pressure and particle displacement information. Moreover, data from morphological studies of the ear suggest that fishes use a vectorial analysis of the direction of motion of the particle velocity component of the sound field to give general information on sound source direction (reviewed in Schellart and Popper, 1992; Popper and Fay, 1993), although a comparison of particle displacement and phase information is required to discriminate between two signals from directly opposite directions (e.g., Schuijf and Buwalda, 1980; Schuijf, 1981). Moreover, it is possible that some fishes use the lateral line for determining the direction of a sound source, particularly when signals are very close to the fish. Under such circumstances, there is a very steep particle displacement field along the length of the lateral line, and comparison of input from different lateral line receptors would give an indication of signal direction (e.g., Denton and Gray, 1989).

\section{RELEVANCE OF FISH DATA TO ZOOPLANKTON}

While studies of fish bioacoustics may not be directly relevant to our understanding of zooplankton use of acoustic and hydrodynamic signals, the basic physical principles and limitations we have learned during the fish studies are certainly germane to zooplankton. However, other than for ichthyoplankton, the issues associated with far field (pressure) detection probably are not relevant to zooplankton, but the near field effects are certainly of relevance especially as they might concern detection of signals 
by sensory systems that might functionally resemble the lateral line. Such systems have been demonstrated to be present in cephalopods (Bleckmann et al., 1991a) and are likely to be present in organisms that comprise the zooplankton. Such detection systems would provide considerable information about the environment immediately around an organism, in a manner that would parallel the idea that fishes use sound to gain an image of their environment (see above). At the same time, mobile zooplankton could also potentially use the same signals to avoid predators.

\section{Acknowledgments}

Portions of the work reported here that was done in my laboratory was supported over the years by NIH, ONR, NSF and NASA. I would like to thank Zhongmin Lu, Pamela Lanford and Jiakun Song for reading earlier versions of this MS.

\section{References}

Bleckmann, H. (1988) Prey identification and prey localization in surface-feeding fish and fishing spiders. In: Sensory Biology of Aquatic Animals, J. Atema, R. R. Fay, A. N. Popper and W. N. Tavolga, eds., SpringerVerlag, New York, pp. 619-641.

Bleckmann, H. (1993) Role of the lateral line in fish behaviour. In: Behaviour of Teleost Fishes, 2nd edition, T. J. Pitcher, ed., Chapman and Hall, London, pp. 177-202.

Bleckmann. H., Budelmann, B. U. and Bullock, T. H. (1991a) Peripheral and central nervous responses evoked by small water movements in a cephalopod. J. Comp. Physiol., A 168, 247-257.

Bleckmann, H., Breithaupt, T., Blickhan, R. and Tautz, J. (1991b) The time course and frequency content of hydrodynamic events caused by moving fish, frogs, and crustaceans. J. Comp. Physiol., A 168, 749-757.

Bregman, A. S. (1990) Auditory Scene Analysis. MIT Press, Cambridge.

Brown, C. H. (1994) Sound localization. In: Comparative Hearing: Mammals, R. R. Fay and A. N. Popper, eds., Springer-Verlag, New York, pp. 57-96.

Buwalda, R. J. A. (1981) Segregation of directional and non-directional acoustic information in the cod. In: Hearing and Sound Communication in Fishes, W. N. Tavolga, A. N. Popper and R. R. Fay, eds. Springer, New York, pp. 139-171.

Buwalda, R. J. A., Schuijf, A., Hawkins, A. D. (1983). Discrimination by the cod of sounds from opposing directions. J. Comp. Physiol., 150, 175-184.

Chapman, C. J. and Hawkins, A. D. (1973) A field study of hearing in the cod, Gadus morhua L. J. Comp. Physiol., 85, 147-167.

Chapman, C. J. and Johnstone, A. D. F. (1974) Some auditory discrimination experiments on marine fish. J. Exp. Biol., 61, 521-528.

Coombs, S., Görner, P. and Münz, H. eds., (1989) The Mechanosensory Lateral Line - Neurobiology and Evolution. Springer-Verlag, New York.

Coombs, S. and Janssen, J. (1989) Peripheral processing by the lateral line system of the mottled sculpin (Cottus bairdi). In: The Mechanosensory Lateral Line - Neurobiology and Evolution, S. Coombs, P. Görner and H. Münz, eds., Springer-Verlag, New York, pp. 409-419.

Coombs, S., Janssen, J. and Montgomery, J. (1992) Functional and evolutionary implications of peripheral diversity in lateral line systems. In: Evolutionary Biology of Hearing, D. B. Webster, R. R. Fay, and A. N. Popper, eds., Springer-Verlag, New York, pp. 267-294.

Coombs, S. and Popper, A. N. (1979) Hearing differences among Hawaiian squir relfish (family Holocentridae) related to differences in the peripheral auditory system. J. Comp. Physiol. 132A, 203-207.

Demski, L., Gerald, G. W. and Popper. A. N. (1973) Central and peripheral mechanisms in teleost sound production. Amer. Zool, 13,1141-1167.

Denton. E. J. and Gray, J. A. B. (1989) Some observations on the forces acting on neuromasts in fish lateral line canals. In: The Mechanosensory Lateral Line - Neurobiology and Evolution, S. Coombs, P. Görner and H. Münz. eds., Springer-Verlag, New York, pp. 229-246.

Denton, E. J. and Gray, J. A. B. (1993) Stimulation of the acoustico-lateralis system of clupeid fish by external sources and their own movements. Phil. Trans. Roy. Soc. Lond. Series B 341,113-127.

Dijkgraaf, S. (1962). The functioning and significance of the lateral line organ. Biol. Rev., 38, 51-105.

Fay, R. R. (1985) Sound intensity processing by the goldfish. J. Acoust. Soc. Am., 78, 1296-1309. 
Fay, R. R. (1988a) Hearing in Vertebrates, A Psychophysics Databook. Hill-Fay Associates, Winnetka, Ill.

Fay, R. R. (1988b) Comparative psychoacoustics. Hear. Res., 34, 295-306.

Fay, R. R. and Popper, A. N. (1974) Acoustic stimulation of the ear of the goldfish (Carassius auratus). J. Exp. Biol., 61, 243-260.

Fay, R. R. and Popper, A. N. (1975) Modes of stimulation of the teleost ear. J. Exp. Biol., 62, 379-387.

Fine, M. L. Winn, H. E. and Olla, B. (1977) Communication in fishes. In: How Animals Communicate. T. A. Sebeok, ed., Indiana University Press, Bloomington, Indiana, pp. 472-518.

Fish, M. P. (1954). The character and significance of sound production among fishes of the western North Atlantic. Bull. Bingh. Oceanograph. College 14, 1-109.

Harris, G. and van Bergeijk, W. A. (1962) Evidence that the lateral line organ responds to near-field displacements of sound sources in water. J. Acoust. Soc. Am., 34, 1831-1841.

Hassan, E. S. (1989) Hydrodynamic imaging of the surroundings by the lateral line of the blind cave fish Anoptichthys jordani. In: The Mechanosensory Lateral Line - Neurobiology and Evolution, S. Coombs, P. Görner and H. Münz, eds., Springer-Verlag, New York, pp. 218-227.

Hawkins, A. D. and Johnstone, A. D. F. (1978) The hearing of the Atlantic salmon, Salmo salar. J. Fish Biol., 13, $655-673$.

Hawkins, A. D. and Sand, O. (1977) Directional hearing in the median vertical plane by the cod. J. Comp. Physiol., 122A, 1-8.

Iversen, R.T. B. (1969) Auditory thresholds of the scombrid fish Euthynnus affinis, with comments on the use of sound in tuna fishing. FAO Conference on Fish Behaviour in Relation to Fishing Techniques and Tactics. FAO Fisheries Rep. No. 62, 3, 849-859.

Jacobs, D.W. and Tavolga, W. N. (1967) Acoustic intensity limens in the goldfish. Anim. Behav, 15, 324-335.

Kalmijn, A. J. (1988) Hydrodynamic and acoustic field detection. In: Sensory Biology of Aquatic Animals, J. Atema, R. R. Fay, A. N. Popper and W. N. Tavolga, eds., Springer-Verlag, New York, pp. 83-130.

Kalmijn. Ad. J. (1989) Functional evolution of lateral line and inner ear systems. In: The Mechanosensory Lateral Line - Neurobiology and Evolution, S. Coombs, P. Görner and H. Münz, eds., Springer-Verlag, New York, pp. 187-216.

Karisen, H. E. (1992a) The inner ear is responsible for detection of infrasound in the perch (Perca fluviatilis). J. Exp. Biol., 171, 163-172.

Karlsen, H. E. (1992b) Infrasound sensitivity in the plaice (Pleuronectes platessa). J. Exp. Biol., 171, 173-187.

McCormick, C. A. (1992) Evolution of central auditory pathways in anamniotes. In: Evolutionary Biology of Hearing, D. B.Webster, R. R. Fay, and A. N. Popper, eds., Springer-Verlag, New York, pp. 323-350

Montgomery, J., Coombs, S. and Halstead, M. In Press. Biology of the mechanosensory lateral line in fishes. Reviews in Fish Biology and Fisheries.'

Moulton, J. M. (1963) Acoustic behaviour of fishes. In: Acoustic Behaviour of Animals, R. -G. Busnel, ed., Elsevier, Amsterdam, pp. 655-693.

Münz, H. (1989) Functional organization of the lateral line periphery. In: The Mechanosensory Lateral Line Neurobiology and Evolution, S. Coombs, P. Görner and H. Münz, eds., Springer-Verlag, New York, pp. 285-297.

Myrberg, A. A. Jr. (1981) Sound communication and interception in fishes. In: Hearing and Sound Communication in Fishes, W. N. Tavolga, A. N. Popper and R. R. Fay, eds., Springer, New York, pp. 395-426.

Myrberg, A. A., Jr. and Riggio, R. J. (1985) Acoustically mediated individual recognition by a coral reef fish (Pomacentrus partitus). Anim. Behav., 33, 411-416.

Myrberg, A. A. Jr. and Spires, J. Y. (1980) Hearing in damselfishes: an analysis of signal detection among closely related species. J. Comp. Physiol, 140, 135-144.

Platt, C. (1983) The peripheral vestibular system in fishes. In: Fish Neurobiology, R. G. Northcutt and R. E. Davis, eds., University of Michigan Press, Ann Arbor, pp. 89-124.

Platt, C. and Popper, A. N. (1981) Otolith organ receptor morphology in herring-like fishes. In: The Vestibular System: Function and Morphology, T. Gualtierotti, ed., Springer-Verlag, New York, pp. $64-76$.

Platt, C., Popper. A. N. and Fay, R. R. (1989) The ear as part of the octavolateralis system. In: The Mechanosensory Lateral Line: Neurobiology and Evolution, S. Coombs, P. Görner and H. Münz, eds., Springer-Verlag: New York, pp. 663-651.

Popper, A. N. (1977) A scanning electron microscopic study of the sacculus and lagena in the ears of fifteen species of teleost fishes. J. Morphol., 153, 397-418.

Popper, A. N. and Coombs. S. (1982) The morphology and evolution of the ear in Actinopterygian fishes. Amer. Zool., 22, 311-328.

Popper, A. N. and Fay, R. R. (1993) Sound detection and processing by fish: critical review and major research questions. Brain, Behav. Evol., 41, 14-38.

Popper, A. N. and Platt. C. (1993) Inner ear and lateral line of bony fishes. In: The Physiology of Fish. D. H. Evans, ed., CRC Press, Boca Raton, Florida, pp. 99-136. 
Popper, A. N., Platt, C. and Edds, P. (1992) Evolution of the vertebrate inner ear: An overview of ideas. In: Evolutionary Biology of Hearing, D. B. Webster, R. R. Fay and A. N. Popper, eds., Springer-Verlag, New York, pp. 49-57.

Popper, A. N., Rogers, P. H., Saidel,W. M. and Cox, M. (1988) The role of the fish ear in sound processing. In: Sensory Biology of Aquatic Animals, J. Atema, R. R. Fay, A. N. Popper and W. N. Tavolga, eds., SpringerVerlag, New York, pp. 687-710.

Popper, A. N. and Tavolga, W. N. (1981) Sound detection and inner ear structure in the marine catfish, Arius felis. J. Comp. Physiol, 144A, 27-34.

Renaud, D. L. and Popper, A. N. (1975) Sound localization by the bottlenose porpoise, Tursiops truncatus. J. Exp. Biol., 63, 569-585.

Retzius, G. (1881) Das Gehörorgan der Wirbelthiere. Vol. I. Samson and Wallin, Stockholm.

Rogers, P. H. and, Cox, M. (1988) Underwater sound as a biological stimulus. In: Sensory Biology of Aquatic Animals, J. Atema, R. R. Fay, A. N. Popper and W. N. Tavolga, eds., Springer-Verlag, New York, pp. 131-149.

Rogers, P. H., Popper, A. N. Cox, M. and Saidel, W. M. (1988) Processing of acoustic signals in the auditory system of bony fish. J. Acoust. Soc. Am., 83, 338-349.

Schellart, N. A. M. and Buwalda, R. J. A. (1990) Directional variant and invariant hearing thresholds in the rainbow trout (Salmo gairdneri). J. Exp. Biol., 149, 113-131.

Schellart, N. A. M. and Popper, A. N. (1992) Functional aspects of the evolution of the auditory system of Actinopterygian fish. In: Evolutionary Biology of Hearing, D. B. Webster, R. R. Fay and A. N. Popper, eds., Springer-Verlag, New York, pp. 295-322.

Schellart, N. A. M., Prints, M. and Kroese, A. B. A. (1992) The pattern of trunk lateral line afferents and efferents in the rainbow trout (Salmo gairdneri). Brain, Behav. Evol., 39, 371-380.

Schellart, N. A. M., Zweijpfenning, R. C. V. J. and Nederstigt, L. J. A. (1984) Convergence of auditory and lateral line processing in the torus semicircular is of the trout (Salmo gairdneri). Soc. Neurosci. Abst., 10,1151.

Schuijf, A. (1975) Directional hearing of cod (Gadus morhua) under approximate free field conditions. J. Comp. Physiol. 98A 307-332.

Schuijf, A. (1981) Models of acoustic localization. In: Hearing and Sound Communication in Fishes, W. N. Tavolga, A. N. Popper and R. R. Fay, eds., Springer, New York, pp. 267-310.

Schuijf, A. and Buwalda, R. J. A. (1980) Underwater localization - A major problem in fish acoustics. In: Comparative Studies of Hearing in Vertebrates, A. N. Popper and R. R. Fay, eds., Springer, New York, pp. 43-77.

Schuijf, A and Hawkins, A. D. (1983) Acoustic distance discrimination by the cod. Nature 302, 143-144.

Siler,W. (1969) Near- and farfields in a marine environment. J. Acoust. Soc. Am., 46, 483-484.

Song, J., Yan, H. Y. Y. and Popper, A. N. (1994) Two types of hair cells in the mechanosensory lateral line receptor: Evidence based on ototoxicity sensitivity. Abst. Assn. Res. Otolaryngol., 17, 75.

Spanier, E. (1979) Aspects of species recognition by sound in four species of damselfish, genus Eupomacentrus (Pisces: Pomacentridae). Z. Tierpsychol., 51, 301-316.

Tavoiga, W. N. (1958) The significance of underwater sounds produced by males of the gobiid fish, Bathygobius soporator. Physiol. Zool., 31, 259-271.

Tavolga,W. N. (1971) Sound production and detection. In: Fish Physiology. W. S. Hoar and D. J. Randall, eds., Academic Press, New York, Vol.V., pp. 135-205.

Tavolga, W. N. and Wodinsky, J. (1963) Auditory capacities in fishes. Pure tone thresholds in nine species of marine teleosts. Bull. Am. Mus. Nat. Hist., 126, 177-240

van Bergeijk, W. A. (1967) The evolution of vertebrate hearing. In: Contributions to Sensory Physiology. W. D. Neff, ed., Academic Press, New York, pp. $1-49$

Wersäll, J. (1960) Vestibular receptor cells in fish and mammals. Acta Otolaryngol. Stockholm Suppl., 163, 25-29 1960.

Winn, H. E. (1967) Vocal facilitation and biological significance of toadfish sounds. In: Marine Bio-Acoustics, II. W. N. Tavolga, ed,. Pergamon Press, Oxford, pp. 283-303 